\title{
Effects of prenatal exposure to a mild chronic variable stress on body weight, preweaning mortality and rat behavior
}

R.J. Cabrera,

E.L. Rodríguez-Echandía, A.S.G. Jatuff and M. Fóscolo

\author{
Laboratorio de Investigaciones Cerebrales and Cátedra de Farmacología, \\ Facultad de Ciencias M édicas, Universidad Nacional de Cuyo, M endoza, \\ Argentina
}

\section{Correspondence \\ E.L. Rodríguez-Echandía \\ Casilla Correo 33 \\ 5500 Mendoza \\ Argentina \\ Fax: +54-261-449-4047 \\ E-mail: sacchio@ raiz.uncu.edu.ar \\ Research supported by the Consejo $\mathrm{Nacional}$ de Investigaciones Científicas y Técnicas (CO NICET, No. PID 334390092).}

Received November 4, 1998 Accepted July 26, 1999

\section{Abstract}

Early stimulation has been shown to produce long-lasting effects in many species. Prenatal exposure to some strong stressors may affect development of the nervous system leading to behavioral impairment in adult life. The purpose of the present work was to study the postnatal harmful effects of exposure to variable mild stresses in rats during pregnancy. Female Holtzman rats were submitted daily to one session of a chronic variable stress (CVS) during pregnancy (prenatal stress; PS group). Control pregnant rats (C group) were undisturbed. The pups of PS and C dams were weighed and separated into two groups $48 \mathrm{~h}$ after delivery. One group was maintained with their own dams (PS group, $\mathrm{N}=70$; $\mathrm{C}$ group, $\mathrm{N}=36$ ) while the other PS pups were cross-fostered with $\mathrm{C}$ dams (PSF group, $\mathrm{N}=47$ ) and the other $\mathrm{C}$ pups were cross-fostered with PS dams ( $\mathrm{CF}$ group, $\mathrm{N}=58$ ). Pups were undisturbed until weaning (postnatal day 28). The male offspring underwent motor activity tests (day 28), enriched environment tests (day 37) and social interaction tests (day 42) in an animal activity monitor. Body weight was recorded on days 2, 28 and 60. The PS pups showed lower birth weight than $\mathrm{C}$ pups (Duncan's test, $\mathrm{P}<0.05$ ). The PS pups suckling with their stressed mothers displayed greater preweaning mortality (C: $23 \%$, PS: $60 \% ; \chi^{2}$ test, $\mathrm{P}<0.05$ ) and lower body weight than controls at days 28 and 60 (Duncan's test, $\mathrm{P}<0.05$ and $\mathrm{P}<0.01$, respectively). The PS, PSF and CF groups showed lower motor activity scores than controls when tested at day 28 (Duncan's test, $\mathrm{P}<0.01$ for $\mathrm{PS}$ group and $\mathrm{P}<0.05$ for $\mathrm{CF}$ and $\mathrm{PSF}$ groups). In the enriched environment test performed on day 37 , between-group differences in total motor activity were not detected; however, the PS, CF and PSF groups displayed less exploration time than controls (Duncan's test, $\mathrm{P}<0.05)$. Only the PS group showed impaired motor activity and impaired social behavior at day 42 (Duncan's test, $\mathrm{P}<0.05$ ). In fact, CVS treatment during gestation plus suckling with a previously stressed mother caused long-lasting physical and behavioral changes in rats. Cross-fostering PS-exposed pups to a dam which was not submitted to stress counteracted most of the harmful effects of the treatment. It is probable that prenatal stress plus suckling from a previously stressed mother can induce long-lasting changes in the neurotransmitter systems involved in emotional regulation. Further experiments using neurochemical and pharmacological approaches would be interesting in this model.
Key words

- Prenatal stress

- Chronic stress

- Body weight

- Behavior

- Mortality

- Rat 


\section{Introduction}

Exposure to some prenatal stress (PS) may affect postnatal maturation of the nervous system and behavior (1-4). It has been reported that daily exposure to some stress during pregnancy can cause fetal resorption in rats and may delay behavioral development in the surviving pups (5). Hyperemotionality and hypersensitivity to conflictive stimuli have been described as permanent behavioral consequences of prenatal stress (1,2,4-8). Regarding humans, prenatal unpredictable stresses can cause neural dysfunctions detectable up to 4 years of age (8).

Both endocrine and behavioral responses to chronic stress in laboratory rats are influenced by the predictability of the stressful stimuli. Quirce et al. (9) showed that the increase of plasma corticosterone due to restraint stress can be gradually attenuated by repeated exposure to this stress, whereas Fride and Weinstock (5) reported that there is no adaptation to variable stresses.

The literature on prenatal stress provides information about the effects of several predictable and unpredictable models of repeated strong stresses $(5,10-12)$. Nonetheless, the effects of chronic exposure to mild variable stresses during prenatal life and the influence of cross-fostering of prenatally stressed pups to nonstressed dams have not been studied.

In the present work, daily exposure to an unpredictable mild stress was applied to adult rats during pregnancy. It is of interest that similar chronic variable stress models cause a characteristic behavioral depression syndrome in nonpregnant rats and have been proposed as animal models of human depression (12-18).

In order to study the influence of maternal stress on the physical and behavioral development of the litter we analyzed the effect of daily exposure of pregnant rats to a model of unpredictable chronic stress reported elsewhere (17), as well as the influ- ence of mothering through cross-fostering of stressed pups to nonstressed dams and nonstressed pups to mothers that had formely received chronic stress.

\section{Material and Methods}

Virgin female rats, 90 days of age (Holtzman strain), weighing 205-230 g were housed in stainless steel cages $(40 \times 27 \times 20$ $\mathrm{cm}$ ) on white poplar shavings and maintained under conditions of controlled temperature $\left(22 \pm 2^{\circ} \mathrm{C}\right)$ and lighting (light on: 5:00-19:00 h). Standard rat chow (Nutric, Córdoba City, Córdoba, Argentina) and water were provided ad libitum.

Two females were mated with one male. Vaginal smears were analyzed daily (9:0011:00 h) and the finding of sperm was considered as day 0 of pregnancy. The males were then removed and the pregnant females were separated into experimental $(\mathrm{PS} ; \mathrm{N}=$ $10)$ and control $(C ; N=8)$ groups and housed in groups of 4-5 in stainless steel cages ( $40 \mathrm{x}$ $27 \times 20 \mathrm{~cm}$ ).

\section{Treatment during pregnancy}

The experimental group was exposed to a daily session of a mild variable stress from day 1 to day 21 of pregnancy. Table 1 shows the stress schedule applied. Though such highly different stressors cannot be considered to be equivalent, all stressors used are known to induce behavioral and endocrine responses in male and female rats. In summary, the stress schedule consisted of 13 days of short stress sessions ( 3 to $20 \mathrm{~min} /$ day), 3 days free, $36 \mathrm{~h}$ of water deprivation, $24 \mathrm{~h}$ of crowding, and about $24 \mathrm{~h}$ of isolation on the day preceding delivery. The strongest stress was water deprivation. However, there is evidence suggesting that 48 $\mathrm{h}$ of water deprivation are needed to cause dehydration in laboratory rats (19). The control group was left undisturbed. On day 20 of pregnancy all females were isolated in individual cages. 


\section{Treatment of newborn pups and housing conditions}

Prenatally stressed and control offspring were sexed and weighed $48 \mathrm{~h}$ after delivery. Each group was divided into two subgroups, one was returned to their own dams and kept undisturbed while nursing ( $\mathrm{C}$ group, $\mathrm{N}=36$; PS group, $N=70$ ) while the other PS pups were cross-fostered to control dams (PSF group, $\mathrm{N}=47$ ) and the other untreated controls were cross-fostered to stressed dams ( $\mathrm{CF}$ group, $\mathrm{N}=58$ ). The body weights of pups assigned to the birth mothers were equivalent to the body weights of pups assigned to the foster mothers. Each suckling group was composed of 8-9 pups of the same experimental condition. The remaining pups were discarded. It has been previously estab- lished that the amount of milk suckled per milking and the quality of milk does not significantly change for litters of 6 to 10 pups (20). Because of the difference in weight between stressed and nonstressed offspring a split-litter design was not used.

\section{Procedures}

Because of the small size and weight of the PS group on day 21 of age all groups were weaned on postnatal day 28 , i.e., 7 days later than normal and preweaning mortality was assessed. The basal motor activity of 12 randomly selected males from each group of surviving rats was then measured for the first time. Female pups were discarded from these experiments. After testing, males were immediately weighed, weaned and housed in

Table 1 - Chronic aleatory stress treatment.

\begin{tabular}{|c|c|c|}
\hline Day & Treatment & Procedure \\
\hline 1 & Noise stress & Cage blows, 3 exposures to 3 blows within $3 \mathrm{~min}$ \\
\hline 2 & Cold stress & Home cage placed in a freezer $\left(-20^{\circ} \mathrm{C}\right)$ for $20 \mathrm{~min}$ \\
\hline 3 & Tail pinch stress & $\begin{array}{l}\text { One trial with the proximal third of the tail pinched with a plastic } \\
\text { clothespin, } 10 \mathrm{~min}\end{array}$ \\
\hline 4 & White noise stress & $95 \mathrm{~dB}, 3$ exposures of $30 \mathrm{~s}$ within $5 \mathrm{~min}$ \\
\hline 5 & Free & Undisturbed \\
\hline 6 & Shaking stress & $\begin{array}{l}\text { Horizontal high-speed shakes in the empty water bath box of a } \\
\text { Dubnoff metabolic shaking incubator for } 20 \mathrm{~min}\end{array}$ \\
\hline 7 & Water deprivation stress & Housing group without water for $24 \mathrm{~h}$ (food pellets ad libitum) \\
\hline 8 & Water deprivation stress & Housing group without enough water for $12 \mathrm{~h}$ (food pellets ad libitum) \\
\hline 9 & Crowding stress & $8 \mathrm{rats} /$ home cage for $24 \mathrm{~h}$ \\
\hline 10 & Restraint stress & $\begin{array}{l}\text { Animals placed in a transparent acrylic cylinder }(5 \times 18 \mathrm{~cm}) \text { with five } \\
\text { holes measuring } 5 \mathrm{~mm} \text { each at the head end and a removable top } \\
\text { at the back end, } 15 \mathrm{~min}\end{array}$ \\
\hline 11 & Forced swim stress & $\begin{array}{l}\text { Individual swimming inside a cylinder }(44 \times 16 \mathrm{~cm} \text { in diameter) with } \\
\text { water }\left(23^{\circ} \mathrm{C}\right) \text { up to a level of } 20 \mathrm{~cm} \text { for } 20 \mathrm{~min}\end{array}$ \\
\hline 12 & Free & Undisturbed \\
\hline 13 & Foot shock stress & $\begin{array}{l}\text { Inescapable electric shocks in a Plexiglas box }(40 \times 27 \times 20 \mathrm{~cm}) \\
\text { with a floor grid consisting of } 1 \text {-cm stainless steel bars spaced } 5 \mathrm{~mm} \\
\text { apart. Shocks average } 1 \mathrm{~mA}, 1-\mathrm{s} \text { duration, } 3 \text { shocks } / \mathrm{min}, 3 \mathrm{~min}\end{array}$ \\
\hline 14 & Lighting stress & $\begin{array}{l}3 \text { individual exposures ( } 1 \mathrm{~min} \text { each) to darkness followed by } \\
\text { overlighting ( } 100-\mathrm{W} \text { lamp, } 50 \mathrm{~cm} \text { above) }\end{array}$ \\
\hline 15 & Noise stress & 3 exposures to 3 blows within $3 \mathrm{~min}$ \\
\hline 16 & Rat blood odor & $\begin{array}{l}\text { Exposure to fresh blood diluted in distilled water } \\
\text { (on a Petri dish) for } 30 \mathrm{~min}\end{array}$ \\
\hline 17 & Restraint stress & Identical to 10 \\
\hline 18 & Free & Undisturbed \\
\hline 19 & Cold stress & Identical to 2 \\
\hline 20 & Isolation stress & Individual housing, $24 \mathrm{~h}$ \\
\hline 21 & Birth stress & Parturition \\
\hline
\end{tabular}


groups of 4 in stainless steel cages $(40 \times 27 \times$ $20 \mathrm{~cm}$ ). These were maintained undisturbed under the standard laboratory conditions described above. The same groups (each $\mathrm{N}=$ 12) were submitted to an enriched environment test in the same arena on day 37. On day 42 the same animals ( $N=12$ /group) were isolated for $24 \mathrm{~h}$ in individual cages and then exposed to a social behavior test in the same apparatus (familiar environment situation). Finally, all rats were reweighed on day 60 .

For all behavioral tests the room was illuminated with two 40-W fluorescent lamps placed $2.5 \mathrm{~m}$ above the test box at $22 \pm 2^{\circ} \mathrm{C}$ room temperature and testing was performed from 12:00 to 14:00 $\mathrm{h}$. The observations were made in a blind-observer manner. At the end of the trials each rat was returned to the home-cage and the testing apparatus was wiped clean. Animals were kept undisturbed until the next test session. The behavioral data are presented for male offspring only. The behavioral tests employed were carried out in the following sequence: motor activity test, enriched environment test and social interaction test. To better detect emotional responses, rats were submitted to each test only once.

Motor activity test. Motor activity was monitored in a 5-min test during which rats were placed singly in the $45 \times 45 \times 20 \mathrm{~cm}$ transparent acrylic cage of an animal activity monitor (OPTO-VARIMEX III, Columbus Instrument International Co., Columbus, $\mathrm{OH}$, USA) equipped with horizontal and vertical screen sensors. Ambulatory movements, nonambulatory movements and vertical movements were recorded via the electrical counters and scored as total motor activity.

Enriched environment test. The animal activity monitor cage described above was enriched with a copper test tube rack previously found to induce exploratory behavior in rats (16). It consists of 3 superimposed circular plates (each $14.5 \mathrm{~cm}$ in diameter and placed $3.5 \mathrm{~cm}$ apart from one another); the upper plates bearing 19 holes of $2 \mathrm{~cm}$ placed $0.7 \mathrm{~cm}$ apart and the lower plate $1 \mathrm{~cm}$ holes. In the center of the upper plate there was a handle. Rats were placed individually in a corner of the test box facing the wall for a 5-min trial. The total motor activity (ambulatory plus non-ambulatory and vertical movements) was automatically recorded. The total time spent in active exploration of the novel object (active contacts, rearing, rising to the upper plate, head dipping, nibbling and crawling between plates) was scored by direct observation in a blind manner. This test was used to analyze motivation for sampling and processing information concerning the relevance of a novel stimulus.

Social interaction test. The animals were housed individually for $24 \mathrm{~h}$ before the test (social deprivation). On the following day two partners were placed simultaneously in the acrylic cage of the animal activity monitor (familiar environment). Each rat was assigned a partner of his own treatment group, matched as closely as possible for body weight. The test lasted $5 \mathrm{~min}$ and an observer who had no knowledge of the prenatal treatment employed scored the total time spent in the following categories of active social behavior: a) social sniffing (the time the animals spent sniffing the fur of the partner, including the anogenital region), b) social grooming (grooming the fur of the partner in the neck and back region), c) mounting (time the animals spent leaning on the partner with both forepaws or crawling over him), d) rubbing (time the animal spent moving towards, and rubbing its body against, the partner or crawling under the partner), e) fighting (time spent rolling, boxing, jumping and biting of animals in very close contact with each other), f) evasive activity (time the animals spent moving away from the partner or pushing it away with its paws). The summed time spent in these behavioral categories was scored as total time spent in active social interactions by both members of each pair (paired-scores). The total motor 
activity of each pair was automatically recorded by the interruptions of the infrared beams as described above. This test reveals the anxiogenic effect of a variety of treatments in rats $(21,22)$.

\section{Statistical analysis}

Between-group differences in parametric variables were analyzed by one-way analysis of variance (ANOVA) and by Duncan's new multiple range test. When results were expressed as proportions, the $\chi^{2}$ test corrected by continuity was applied. Results are reported as means \pm SEM. A probability of less than 0.05 was considered significant.

\section{Results}

\section{Effects of PS on preweaning mortality}

The number of pups delivered by each dam was statistically similar in stressed and control groups (C: $11.7 \pm 0.85$, PS: $11.3 \pm$ 0.72 ) and physical malformations were not apparent in any pup. Preweaning mortality, however, was higher in the PS group (C: 23\%, PS: $60 \%$ ). This difference between C and PS groups reached significance $\left(\chi^{2}\right.$ test, $\mathrm{P}<0.05)$. The PSF group, however, showed preweaning mortality scores similar to those of the $\mathrm{CF}$ and $\mathrm{C}$ groups (PSF: 7\%, CF: 14\%).

\section{Effects of PS on body weight}

Body weight of male pups at day 2 after delivery was affected by prenatal treatment (Figure 1). Between-group differences were significant due to the lower weight of the PS group of males $(\mathrm{P}<0.05)$. When PS males were reweighed on day 28 and 60, the PS group continued to show a significantly lower body weight than control males (Duncan's test, $\mathrm{P}<0.05$ and $\mathrm{P}<0.01$, respectively). This was therefore a long-lasting effect of the PS treatment. Figure 1 shows that body weight of $\mathrm{C}$ and CF males were similar on days 28 and 60. PSF males weighed slightly more than $\mathrm{C}$ and $\mathrm{CF}$ males on day $60(\mathrm{P}<0.05)$.

\section{Effects of PS on spontaneous motor activity}

Between-group differences were found when motor activity was measured for the first time on day $28\left(\mathrm{~F}_{(3,32)}=8.88, \mathrm{P}<0.005\right)$. Figure 2 shows that PS, CF and PSF males displayed lower total motor activity scores than the $\mathrm{C}$ group (Duncan's test, $\mathrm{P}<0.01$ for $\mathrm{PS}$ group and $\mathrm{P}<0.05$ for $\mathrm{CF}$ and $\mathrm{PSF}$ groups).

\section{Effects of PS on enriched environment test responses}

When total motor activity was measured on day 37 , in the familiar cage of the animal

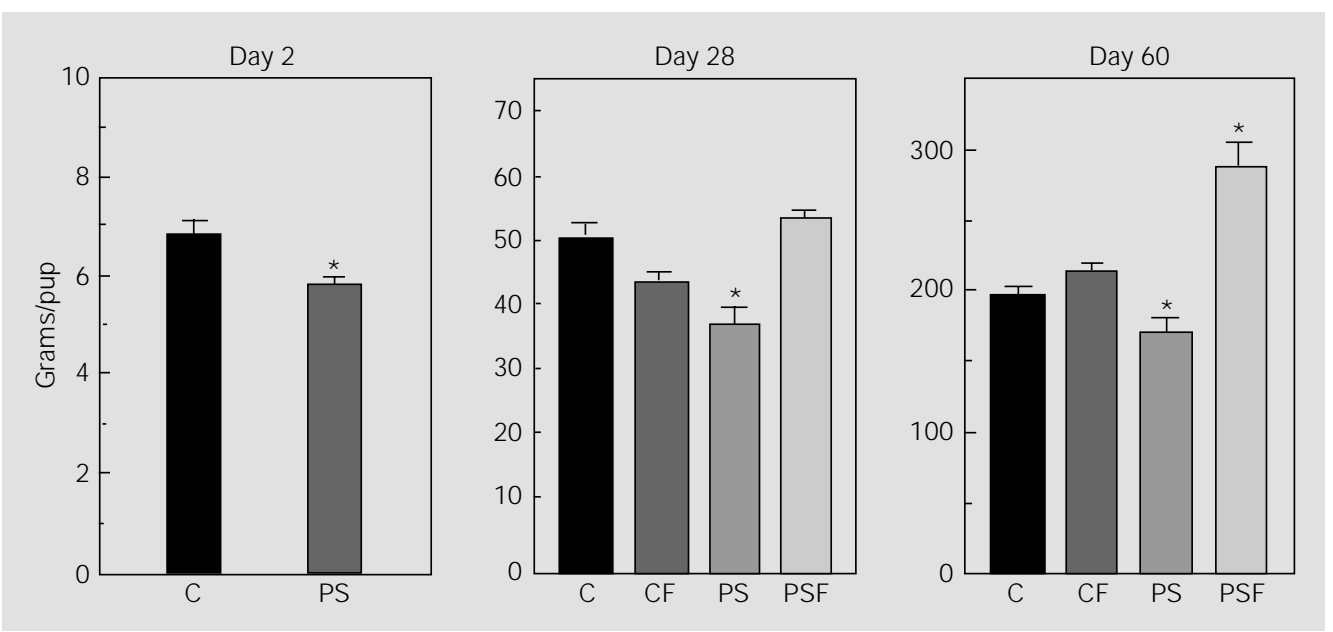

Figure 1 - Body weight (g/pup) at days 2, 28 and 60 of age ( $\mathrm{N}=12$ for each group). The PS group showed lower weight than controls at all ages. C: Controls; CF: control-fostering; PS: prenatal stress; PSF: prenatal stressfostering (means \pm SEM). $* \mathrm{P}<0.05$ compared to controls (Duncan's test). 
activity monitor enriched with a novel object, between-group differences were not detected (results not shown). However, between-group differences in time spent exploring the novel object were significant $\left(\mathrm{F}_{(3,32)}=4.19, \mathrm{P}<0.025\right)$. Figure 2 shows that PS, CF and PSF males displayed less exploration time than controls (Duncan's test,

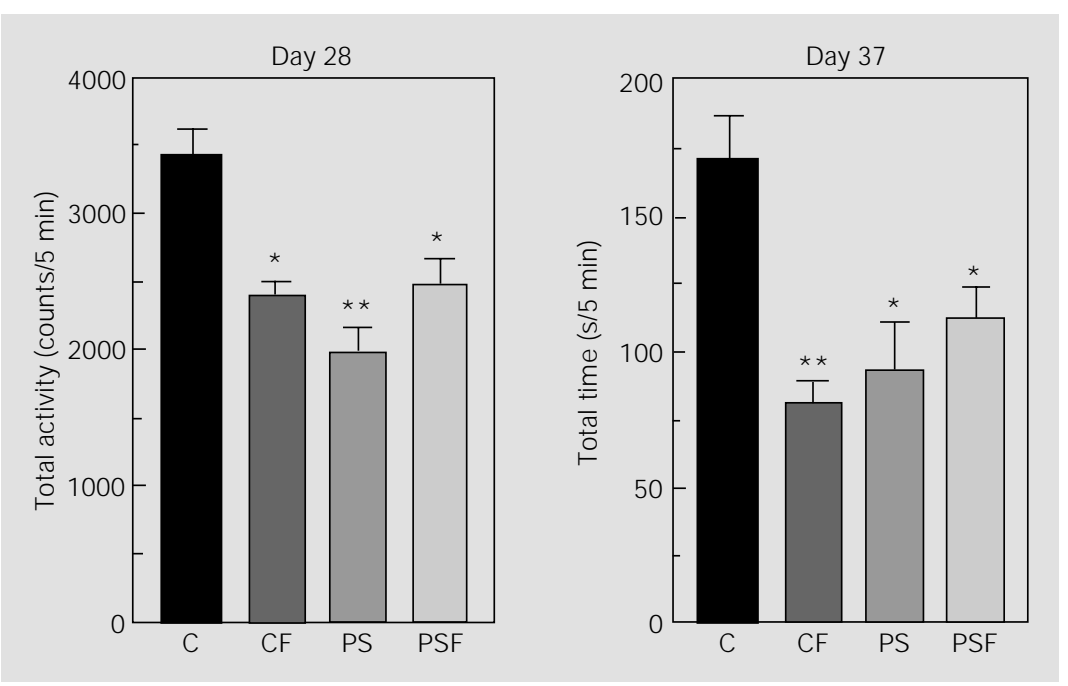

Figure 2 - Day 28: Total motor activity (counts/5 $\mathrm{min}$ ) ( $\mathrm{N}=12$ for each group). All experimental groups displayed less motor activity than controls. Day 37: Enriched environment test showing the scores of total time spent exploring the novel object ( $\mathrm{s} / 5 \mathrm{~min} ; \mathrm{N}=12$ for each group). All experimental groups showed lower exploration time than controls. C: Controls; CF: control-fostering; PS: prenatal stress; PSF: prenatal stress-fostering (means $\pm \mathrm{SEM}$ ). $* \mathrm{P}<0.05$ and $* * \mathrm{P}<0.01$ compared to controls (Duncan's test).
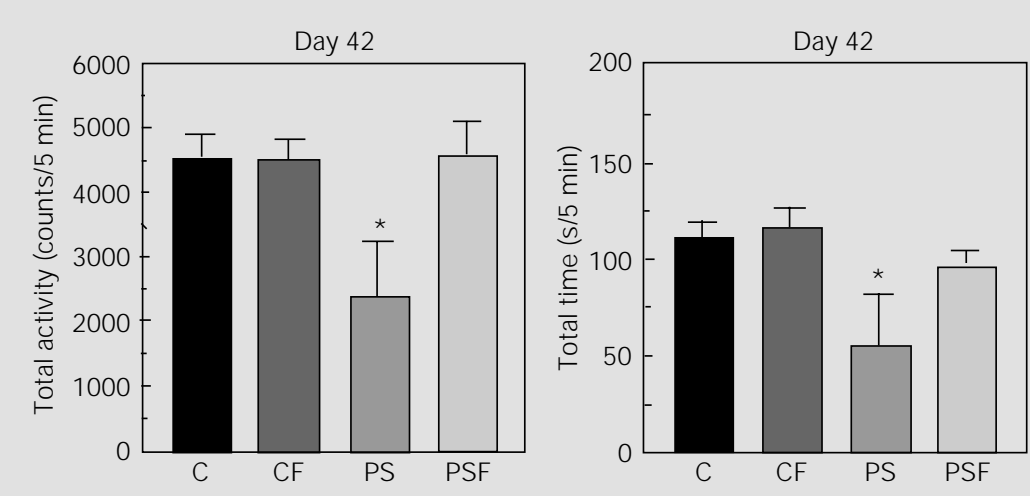

Figure 3 - Social behavior test performed after $24 \mathrm{~h}$ of social isolation at day 42 of age showing total motor activity (counts/5 min) and total time spent ( $\mathrm{s} / 5 \mathrm{~min}$ ) in active social interactions by pairs of controls (C), control-fostering (CF), prenatally stressed (PS) and prenatally stressed-fostered rats (PSF). Only the PS group displayed lower motor activity and lower time spent in social behavior than controls. Means $\pm \mathrm{SEM} . * \mathrm{P}<0.05$ compared to controls (Duncan's test).
$\mathrm{P}<0.05$ for all groups).

\section{Effects of PS on social behavior}

This test was performed on day 42 in the same arena used for testing on days 28 and 37 of age. Between-group differences were observed in the paired scores of total motor activity (Figure 3), due to the lower scores of the PS group (Duncan's test, $\mathrm{P}<0.05$ ). Comparison of the paired scores of total time spent in active social interactions also showed between-group differences $\left(\mathrm{F}_{(3,59)}=6.43\right.$, $\mathrm{P}<0.01$ ). Figure 3 shows that this was due to the lower scores of social interactions demonstrated by the PS group only (Duncan's test, $\mathrm{P}<0.05$ ).

\section{Discussion}

There is abundant literature concerning the behavioral depression syndrome caused in rats by the chronic variable stress model used in the present study. This stress model causes a consumatory and motivational deficit, which has been interpreted as anhedonia $(12,16,18)$, blocks the behavioral activation induced by noise stimulation (15), blocks holeboard exploration (13), increases anxiety levels in emergence tests (17), impairs forced swimming behavior, i.e., increases behavioral despair $(13,17)$ and increases basal levels of the stress-sensitive hormones, corticosterone and prolactin in both male and female rats $(17,23)$. This syndrome, which lasts up to day 4 post-treatment (17), has been used as an animal model of human depression reactions (15-17). The present results show that when this stress model was applied during pregnancy it did not cause fetal resorption or physical malformations in pups. However, the prenatally stressed pups showed lower birth weights than controls. These results are in contrast with those of Fride and Weinstock (5) who found that chronic exposure to lighting stress during pregnancy caused fetal resorption and in- 
creased body weight in the surviving newborn pups. The former effect may be peculiar for lighting stress, which was not included in our variable stress schedule. The latter might not be due to stress only since it is known that newborn pups of small litters weigh more than pups of large litters.

Body weight at the end of lactation was also lower than in controls in the PS pups maintained with their own previously stressed dams. In this group a significant increase of preweaning mortality was also found. It is thus possible that stress during pregnancy could have altered the hormonal balance and thus interfered with subsequent lactation and maternal care. This is supported by the fact that fostering of PS offspring to control dams prevented both the reduced weaning weight and the high preweaning mortality observed in the PS offspring assigned to the birth mothers. Additionally, fostering of control pups to previously stressed dams caused a trend for lower body weight at weaning. It is of interest that this was a long-lasting effect since the PS group weighed less than the $\mathrm{C}$ group even during adulthood, i.e., at day 60 of life. However, the PSF group had higher body weight than controls at day 60 . This unexpected result might be related to an effect of treatment on food intake during adulthood. Additional research may solve this problem.

The PS group showed motor hypoactivity in the tests performed on day 28 of age. If this group had lower birth weight and was exposed to reduced lactation this might suggest that only those pups with low activity, and thus low energy demands, survived. If such were the case, the low activity levels in the PS group may have been due to a selection of which animals survived, and not to a direct effect of prenatal stress per se. However, low levels of preweaning mortality were detected in the $\mathrm{C}$ group fostered to stressed mothers and in the PS group fostered to unstressed mothers, but both fostered groups showed low motor activity as well. It is thus possible that both prenatal stress and/or suckling with a previously stressed mother might cause retardation of locomotion development rather than a selection bias in the sampling. Though pup locomotion at day 37 and day 42 was not comparable since the animals were submitted to different tests, this is supported by the fact that a locomotor deficit was apparent when CF, PS and PSF animals were submitted to an enriched environment test on day 37 of age. This study does not look at cross-fostering, in general, but at a specific situation where prenatally stressed rats are cross-fostered to control dams and control pups crossfostered to stressed dams. With this experimental design, effects due to cross-fostering alone cannot be determined. However, it may be of interest to point out that Peters (24) previously reported that fostering per se may impair locomotion in weaning age rats.

The enriched environment test performed on day 37 of age revealed that the PS, CF and PSF groups spent less time exploring the novel object than controls. Since all groups showed similar motor activity scores, this finding is consistent with reduced motivation for sampling and processing information concerning the relevance of a new stimulus and/or development of high anxiety levels in novel situations (13). The chronic variable stress model used has been reported to increase anxiety levels in female rats (17) and it has been reported that prenatal maternal anxiety can increase offspring emotionality (1). The present results suggest that prenatal stress, reduced lactation and/or reduced maternal care can also increase offspring emotionality.

When rats were exposed to a social behavior test in a familiar environment (day 42) after $24 \mathrm{~h}$ of social isolation, the PS animals reared with their own mothers showed lower scores of motor activity and less total time spent in active social interactions than controls. In this test, the CF and PSF groups behaved as controls. Since anxi- 
ety is known to block social behavior in a familiar environment $(21,22)$ this suggests that prenatal stress plus suckling from a previously stressed mother can induce a longlasting increase in rat emotionality. This is supported also by the fact that chronic prenatal stress decreases benzodiazepine binding as well as $3 \mathrm{H}-5-\mathrm{HT}$ binding in the hippocampus of rat pups $(2,24)$. Both the neurotransmitter systems and the hippocampus are known to be involved in emotional regulation $(23,25)$.

In conclusion, exposure to daily variable stresses during prenatal development causes transient and long-lasting deletereous effects in rats, as also reported by others $(1,2,4-7)$. The PS rats which were exposed to three adverse conditions, i.e., prenatal aleatory stress, lower birth weight (as a consequence of prenatal stress) and suckling with a previously stressed mother, displayed a) a high rate of preweaning mortality, b) lower body weight at weaning, c) lower motor activity as infants and lower exploration of a novel object in periadolescent life, d) lower weight at day 60 of life and e) higher emotionality than controls as adults. The PSF young males which were exposed to two adverse conditions, i.e., prenatal stress and low birth weight, also displayed lower motor activity on day 28 and lower exploration than controls on day 37. These, however, behaved as controls in adulthood. Therefore, fostering of PS rats to control mothers, i.e., suckling with a previously nonstressed dam, prevented the longlasting effects on body weight, motor activity and emotionality. Many authors have shown that early rehabilitation from some prenatal deleterious influences may improve physical and behavioral development in postnatal life (10,26-28).

Finally, it is probable that prenatal stress plus suckling from a previously stressed mother can induce long-lasting changes in the neurotransmitter systems involved in emotional regulation. Further experiments using neurochemical and pharmacological approaches in the same model would be interesting.

\section{Acknowledgments}

The authors wish to thank Dr. Fabio Sacerdote for editorial help.

\section{References}

1. Ader R \& Belfer M (1962). Prenatal maternal anxiety and offspring emotionality in the rat. Psychological Reports, 10: 711-718.

2. Fride $E$, Don $Y$, Garvish $M \&$ Weinstock $M$ (1985). Prenatal stress impairs maternal behavior in a conflict situation and reduces hippocampal benzodiazepine receptor. Life Sciences, 36: 2103-2109.

3. Havlet J \& Werboff J (1963). Postnatal effect of control fluid administered to gravid rats. Psychological Reports, 12: 127-131.

4. Herrenkchl LR (1986). Prenatal stress disrupts reproductive behavior and physiology in offsprings. Annals of the New York Academy of Sciences, 474: 120-128.

5. Fride E \& Weinstock M (1984). The effects of prenatal exposure to predictable or unpredictable stress on early development in the rat. Developmental Psychobi- ology, 17: 651-660.

6. Hultching $D \& \&$ Gibbon J (1970). Preliminary study of behavioral and teratogenic effects of the stress procedures administered during different periods of gestation in the rat. Psychological Reports, 26: 235-246.

7. Masterpascua F, Chapman RH \& Lare RK (1976). The effects of prenatal psychological stress on the sexual behavior and reactivity of male rats. Developmental Psychobiology, 9: 403-411.

8. Stott H (1973). Follow-up study from birth of the effects of prenatal stress. Developmental Medicine and Child Neurology, 15: 770-787.

9. Quirce C, Odio M \& Solano J (1962). The effect of predictable and unpredictable schedules of physical restraint upon rats. Life Sciences, 28: 1897-1902.

10. Ward IL \& Reed J (1985). Prenatal stress and prepuberal social rearing conditions interact to determine sexual behavior in male rats. Behavioral Neurosciences, 99: 301-309.

11. Weinstock $M$, Fride $E$ \& Hertzberg $R$ (1988). Prenatal stress effects on functional development of the offsprings. Progress in Brain Research, 73: 319-331.

12. Willner P, Muscat R \& Papp M (1992). Chronic mild stress-induced anhedonia: a realistic animal model of depression. Neuroscience and Biobehavioral Reviews, 16: 525-534.

13. García Marquez C \& Armario A (1987). Interaction between chronic stress and clomipramine treatment in rats. Effects on exploratory activity, behavioral despair, and pituitary adrenal function. Psychopharmacology, 93: 77-81.

14. González AS, Rodríguez Echandía EL, Cabrera R, Fóscolo MR \& Fracchia LN 
(1990). Neonatal chronic stress induces subsensitivity to chronic stress in adult rats. I. Effects on forced swim behavior and endocrine responses. Physiology and Behavior, 47: 735-741.

15. Katz RJ (1981). Animal model and human depressive disorders. Neuroscience and Biobehavioral Reviews, 5: 231-246.

16. Katz RJ (1982). Animal model of depression: Pharmacological sensitivity of hedonic deficit. Pharmacology, Biochemistry and Behavior, 16: 965-968.

17. Rodríguez Echandía EL, González AS, Cabrera RJ \& Fracchia LN (1988). A further analysis of behavioral and endocrine effects of unpredictable chronic stress. Physiology and Behavior, 43: 789-795.

18. Sampson D, Muscat G, Phillips G \& Willner $P$ (1992). Decreased reactivity to sweetness following chronic exposure to mild unpredictable stress or acute administration of Pimozide. Neuroscience and Biobehavioral Reviews, 16: 519-524.

19. Silverman P (1978). Animal Behavior in the Laboratory. Chapman and Hall, London.

20. Yagil R, Etzion Z \& Berlyne GM (1976). Changes in rat milk quantity and quality due to variations in litter size and high ambient temperature. Laboratory Animal Science, 26: 33-37.

21. File SE \& Hyde J RG (1979). A test of anxiety that distinguishes between the actions of benzodiazepines and those of other mild tranquilizers and stimulants. Pharmacology, Biochemistry and Behavior, 11: 65-69.

22. File SE \& Hyde J RG (1979). Evidence that piracetam has an anxiolytic action. J ournal of Affective Disorders, 1: 227-235.

23. Barlow S, Knigth A \& Sullivan F (1978). Plasma corticosterone responses to stress following chronic oral administration of diazepan in the rat. J ournal of Pharmacology, 31: 23-26.

24. Peters D (1986). Prenatal stress: Effect on development of rat brain serotonergic neurons. Pharmacology, Biochemistry and Behavior, 24: 1377-1382.

25. Chopin P \& Britey N (1987). Animal models of anxiety: The effect of compounds that modify $5-\mathrm{HT}$ neurotransmission. Trends in Pharmacological Sciences, 8: 383-388.

26. J offe J M (1972). Postnatal experience and the detection of the effects of prenatal stress on behavior: a reply to Archer and Blackman. Developmental Psychobiology, 5: 389-390.

27. Myers J N (1962). Critical period for the facilitation of exploratory behavior by infantile experience. J ournal of Comparative and Physiological Psychology, 55: 1099-1101.

28. Smythe J W, McCormick CM, Rochford J \& Meaney MJ (1994). The interaction between prenatal stress and neonatal handling on nociceptive response latencies in male and female rats. Life Sciences, 20: 971-974. 